\title{
Essential tremor: the most common form of cerebellar degeneration?
}

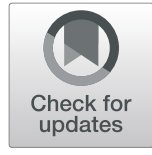

Elan D. Louis ${ }^{1 *}$ and Phyllis L. Faust ${ }^{2}$

\begin{abstract}
Background: The degenerative cerebellar ataxias comprise a large and heterogeneous group of neurological diseases whose hallmark clinical feature is ataxia, and which are accompanied, to variable degrees, by other features that are attributable to cerebellar dysfunction. Essential tremor (ET) is an exceptionally common neurological disease whose primary motor feature is action tremor, although patients often manifest intention tremor, mild gait ataxia and several other features of cerebellar dysfunction.

Main Body: In this paper, we review the abundant evidence derived from clinical, neuroimaging and postmortem studies, linking ET to cerebellar dysfunction. Furthermore, we review the combination of clinical, natural history and postmortem features suggesting that ET is neurodegenerative. We then compare the prevalence of ET (400 - 900 cases per 100,000) to that of the other cerebellar degenerations (ranging from $\leq 0.5-9$ cases per 100,000, and in composite likely to be on the order of 20 cases per 100,000) and conclude that ET is 20 to 45 times more prevalent than all other forms of cerebellar degeneration combined.
\end{abstract}

Conclusion: Given the data we present, it is logical to conclude that ET is, by far, the most common form of cerebellar degeneration.

Keywords: Essential tremor, cerebellar degeneration, spinocerebellar ataxia, cerebellum, neurodegeneration, prevalence

\section{Background}

Degenerative cerebellar ataxias comprise a heterogeneous group of disorders whose hallmark clinical feature is ataxia (i.e., problems with force and timing of motion) and which are characterized on postmortem by various degrees of cerebellar degeneration; the list of such degenerative disorders of the cerebellum is extensive [1-7]. While the disorders are clinically heterogeneous, what they have in common is a related set of features that are referable to cerebellar dysfunction. Among several features, these can include gait ataxia, intention tremor, and eye movement abnormalities [1-6].

\footnotetext{
* Correspondence: elan.louis@Utsouthwestern.edu

'Department of Neurology and Therapeutics, University of Texas Southwestern, Dallas, TX, USA

Full list of author information is available at the end of the article
}

Although there are numerous forms of autosomal dominant and autosomal recessive spinocerebellar ataxias (SCAs), along with a plethora of other disorders of cerebellar degeneration that include both hereditary and acquired forms [2, 7], both individually and in composite, these disorders are characterized by modest prevalence [7-9].

The prevalence of the autosomal dominant SCAs has been estimated to be 1 - 9 cases per 100000 people, and over 40 subtypes are now genetically defined [5, 8-15]. Among these, SCA2 and SCA3 are the most common subtypes worldwide; SCA1, SCA6, SCA7 and SCA8 often make up a relatively larger proportion of SCAs and the remainder tends to be rarer, although there is variation in prevalence from country to country $[8,10$, $11,13,15]$. Autosomal recessive ataxias are similarly characterized by a low prevalence, with Friedreich's 
ataxia being the most common (prevalence $=0.5-5 /$ 100,000) $[13,16,17]$. Acquired degenerative ataxias are similarly rare - multiple system atrophy $(3.4-4.3 / 100$, 000) $[18,19]$, paraneoplastic cerebellar degeneration $(1.2 / 100,000)[20]$, and ataxia with vitamin E deficiency $(0.06 / 100,000)$ [21].

Essential tremor (ET) is a common neurological disease [22]. Its primary motor feature is action tremor [23], although patients often manifest intention tremor [24-26], mild gait ataxia [27] and other features of subtle cerebellar dysfunction [28]. The pathophysiology is of ET unclear, and is likely heterogeneous. Recent work has recast it as one that is often due to cerebellar and cerebellar pathway dysfunction [28-36] as well as one that is likely degenerative [29, 37-51].

Although there are published scholarly reviews that have focused on the links between ET and the cerebellum $[28,30-32,52,53]$, other reviews that focused on its possible degenerative nature [29, 37, 39, 40,47], and others that elucidated its high prevalence [22, 54], there is no work that has synthesized all of these loose threads and put them together in one place to support a new thesis - that ET is the most common form of cerebellar degeneration. The goals of this paper are to briefly review the evidence that ET is linked to the cerebellum, that ET is a degenerative disease, and that it has a very high prevalence. We then compare the prevalence of ET to that of other forms of cerebellar degeneration, as this has not yet been formally done. We then synthesize these different data streams to support the thesis that ET is the most common neurodegenerative disorder of the cerebellum.

\section{Methods}

\section{Literature Review}

One of the authors (E.D.L.) conducted a PubMed search on April 22, 2020. The goals of this search were to systematically identify papers that provided [1] data on the links between ET and the cerebellum, [2] data and discussion on the degenerative hypothesis of ET, and [3] data on the prevalence of ET. It was not a systematic search of all papers on disease mechanisms in ET, although the only other mechanistic disease model for ET is the olivary hypothesis, which has fallen out of favor in recent years [55-57]. During this search, the author searched abstracts of published papers, crossing the term "essential tremor" with a series of second terms, which yielded the following numbers of papers: essential tremor + cerebellum $(n=376)$, essential tremor + cerebellar $(n=459)$, essential tremor + degeneration $(n=$ 124), essential tremor + degenerative $(n=63)$, essential tremor + neurodegeneration $(n=68)$, and essential tremor + neurodegenerative $(n=242)$. These papers were reviewed for relevant content and cited in this paper if relevant.

\section{Definitions}

Prevalence is the proportion of the population having a disease, and it includes both crude and adjusted prevalence. Crude prevalence refers to the actual proportion of cases, and it may be contrasted with adjusted prevalence (e.g., age-adjusted prevalence), which is a proportion that has undergone statistical transformation to permit fair comparison with the prevalence in other groups that differ in some characteristic such as age or gender.

\section{Main Text}

High Prevalence of ET - Review of the Data

$\mathrm{ET}$ is one of the most common movement disorders and the most common form of tremor. A review of 28 population-based prevalence studies from 19 countries broadly examined the prevalence of ET globally [22]. In a meta-analysis, the prevalence among all ages was $0.9 \%$ (i.e., 900 per 100,000) [22]. In additional descriptive analyses, the crude prevalence among all ages was $0.4 \%$ (i.e., 400 per 100,000) [22]. Prevalence increased markedly with age, and especially with more advanced age [22]. In the meta-analysis, prevalence among persons age 65 years or older was $4.6 \%$ (i.e., 4,600 per 100,000 ), and in additional descriptive analyses, the median crude prevalence among those age $60-65$ and older was $6.3 \%$ (i.e., 6,300 per 100,000 ) [22]. In one study of those age 95 and older, the crude prevalence was $21.7 \%$ (21,700 per $100,000)[22,58]$. In the United States alone, an estimated 7 million of individuals are affected, representing $2 \%$ of the entire population [54].

\section{ET - Review of its Links to the Cerebellum}

In this section, we review the clinical, neuroimaging, and postmortem studies that point towards a link between ET and the cerebellum.

\section{Clinical}

A complete discussion of the clinical features that link ET to the cerebellum may be found elsewhere [28]. In approximately one-half of patients with ET, the kinetic tremor may have an intentional component [24]. This is of interest to the present discussion because intention tremor has canonically been viewed as a sign of cerebellar dysfunction. Thus, in these patients, during the finger-nose-finger maneuver, the tremor amplitude increases when the patient's finger approaches his/her own nose or the examiner's finger $[24,59,60]$. Furthermore, intention tremor is not restricted to the upper limbs in ET. Thus, an intention tremor of the head is seen in as many as $10 \%$ of ET patients (e.g., tremor 
occurs in the neck as the head moves towards a target, for example, while moving the neck forward to facilitate drinking from a cup) [61]. Intention tremor is also more prevalent in the legs of ET patients than in controls, observed in 1-in-4 ET patients [62].

Apart from tremor, a number of other motor features have been described in ET patients and these features point towards an underlying abnormality of the cerebellum or its projections. The most clinically-evident of these clinical features is gait ataxia, which is generally mild [27, 63-70]. In some ET patients, however, gait ataxia can be of moderate severity [71]. In a study of a 104 ET patients and 40 controls [72], in which patients were studied using quantitative gait analysis, ET gait was characterized under standard walking conditions by slower gait speed, problems with dynamic balance and gait temporal asymmetry. This constellation of impairments is similar to that which is seen in patients with cerebellar ataxic gait $[27,73-75]$. Although the gait abnormality in $\mathrm{ET}$ is milder than that seen in patients with most forms of SCA, it does have clinical and functional consequences, with studies indicating that ET patients may exhibit reduced functional mobility both in terms of self-reported measures of gait confidence and in performance-based measures $[27,68,69]$ and increased numbers of self-reported falls [69].

There are several other motor abnormalities that point to what is likely to be a more pervasive underlying abnormality of cerebellar function in ET. First, in a study of 14 ET patients and 11 controls, eye movements were recorded using a scleral search-coil technique, and vestibular function was assessed using electro-oculography [76]. ET patients demonstrated several oculomotor deficits that may have been indicative of cerebellar dysfunction - impaired initiation of smooth pursuit and pathological changes in the vestibulo-ocular reflex [76]. Of additional interest is that these oculomotor abnormalities were particularly evident among those ET patients who also exhibited intention tremor [76], which as noted above canonically has been viewed as a sign of cerebellar dysfunction. The presence of sub-clinical eye movement abnormalities in ET patients has been confirmed in several additional studies [77, 78]. Second, several studies have revealed abnormalities in limb motor behavior in ET [79-83]. Thus, a study of eye-hand coordination that compared $12 \mathrm{ET}$ patients to 14 controls demonstrated abnormal kinematic changes during the early phase of pointing movements, which are also a feature of underlying cerebellar disease [81]. Another study compared $15 \mathrm{ET}$ patients with 11 controls in terms of repetitive finger tapping movements [82]. ET patients demonstrated a longer touch duration, a lower intertapping interval and greater temporal variability when compared with controls [82]. During a predictive motor- timing task, which involved mediated interception of a moving target, some ET patients (i.e., the subgroup with head tremor) and patients with SCA were significantly worse at interception than were patients with Parkinson's disease and controls, suggesting the presence of a fundamental problem with predictive motor timing [79, 83]. The regularity and the maximum frequency of auditory paced repetitive movements was also compared in 34 ET patients and 41 healthy controls - there was greater variability of rhythmic finger tapping and alternating hand movements in ET patients than controls, and timing of rhythmic movements of the two hands was disturbed to the same degree [80]. These results suggested the presence of a marked deficit of eventbased rhythm generation in ET, and given the role of the cerebellum in motor timing $[52,84,85]$, these provide further evidence of bilateral cerebellar dysfunction [80]. Third, motor learning also appears to be impaired in ET [86, 87]. In one study, investigators used conditioning of the eyeblink reflex to assess motor learning in 23 ET patients and 23 controls - the ability to acquire conditioned eyeblink responses was significantly reduced in ET [86]. In another study, investigators studied 10 ET patients and 9 controls using an eyeblink reflex conditioning paradigm, and motor learning was again abnormal in ET, again, likely reflecting pathological involvement of the cerebellum [87].

Aside from motor features, there is a growing literature that demonstrates the presence of non-motor features in patients with ET [88]. Among these is cognitive impairment, which may range from mild to marked [89]. While some of this impairment likely has its basis in degenerative pathology in the cerebral cortex [90, 91], some is also likely based in the cerebellum, as a cerebellar cognitive affective syndrome is well-known to occur and includes hallmark deficits in executive function [92]. That executive dysfunction is a common feature of the cognitive impairment of both ET and cerebellar-related cognitive dysfunction further suggests links between ET and the cerebellum [89].

In summary, as reviewed above, a range of clinical features link ET to a dysfunction of the cerebellar system. There are others. These include the observed resolution of ET in a patient after cerebellar stroke as well as the observation that cerebellar outflow pathways are the focus of several highly-effective surgical approaches to ET [28, 93]. As noted above, a detailed elaboration of the clinical features that link ET to the cerebellum may be found elsewhere [28].

\section{Neuroimaging}

Numerous neuroimaging studies have compared ET patients to controls [30, 34, 94-96]. Although there is some variation across studies, the most consistently 
involved brain structure is the cerebellum [30, 34, 9496]. These studies have employed a broad array of methods, including magnetic resonance (MR) volumetry, MR spectroscopy, diffusion-weighted and diffusion tensor imaging, functional MR imaging, other MR imaging, and positron emission tomography (PET) [94]. This literature will be briefly reviewed.

In a comprehensive review published in 2014 [94], the data from the voxel based morphometry studies (i.e., MR volumetry) were somewhat mixed, yet the majority of studies (i.e., four of six [97-102]) reported a reduction in cerebellar volume in ET and, in particular, among the subgroup of ET patients who had head tremor. More recently, MRI volumetry analyses have reported similar reductions in specific cerebellar lobules in ET patients in comparison with controls [103].

MR spectroscopy data from two studies $[104,105]$ provide evidence that there is, at a minimum, neuronal dysfunction in the cerebellum in patients with ET, and quite possibly, neuronal loss [94].

In the 2014 review, seven studies [106-112] used diffusion imaging to compare ET patients to controls, using a variety of approaches, including a whole brain voxelby-voxel comparison as well as a region of interest approach, targeting areas involved in the olivary-cerebellar-thalamic network [94]. Five of seven diffusion imaging studies demonstrated differences between ET cases and controls, and the two studies with null results had important methodological limitations [94]. More recent studies similarly show diffusion tensor changes in the ET vs. control cerebellum [51]. Hence, the bulk of evidence from the diffusion tensor imaging literature demonstrates that some orientation-dependent aspect of the microstructure of the tissue in ET is abnormal [94]. The bulk of these studies show evidence of axonal changes in the cerebellum, although more widespread changes have been noted as well [94].

In the comprehensive review [94], five studies were reported to have used functional MR imaging to study ET [113-117], with the first of these being a study of 12 ET patients and 15 controls in 1997, showing that ET is associated with an additional contralateral cerebellar pathway activation and overactivity in the cerebellum, red nucleus, and globus pallidus, without significant intrinsic inferior olivary nucleus activation [114]. Several of the other fMRI studies have similarly shown abnormalities in the cerebellar-thalamic network in patients with ET [113, 117]. More recent functional MRI studies have also detected changes in the ET cerebellar hemispheres and/or cerebellar vermis, among a limited number of other cortical and subcortical regions, in ET cases vs. controls $[118,119]$.

A sizable number of studies [120-125] have used PET to provide information about regional cerebral blood flow, regional glucose metabolism and regional binding of a variety of radiopharmaceutical compounds in patients with ET [94]. The most consistent finding in these studies is the localization of changes in blood flow to the cerebellum, although a number of other structures within the motor system, including the thalamus and red nucleus, have been implicated in selected studies as well. In another study [126], the authors performed ${ }^{11} \mathrm{C}$ flumazenil PET to calculate the distribution volume of the $\mathrm{GABA}_{\mathrm{A}}$ complex, in eight ET cases and 11 controls. In ET, there was a significant increase in binding of ${ }^{11} \mathrm{C}$ flumazenil at the benzodiazepine receptor site of the $\mathrm{GABA}_{\mathrm{A}}$ receptor in the cerebellum, the ventrolateral thalamus, and the lateral premotor cortex [126].

In summary, the most consistently involved structure in which abnormalities are seen in ET is the cerebellum, although a variety of studies also show abnormalities in other brain regions, many of which are part of the cerebellum's tremor outflow pathway.

\section{Pathological}

Despite its extraordinarily high prevalence, the pathomechanisms of ET have been elusive [47, 127-129]. Even the localization of the site of primary pathology within the brain has been a major challenge. In part, this was due to the lack of postmortem studies; indeed, during the 100-year period from 1903 to 2003, there were only 15 published postmortems [130], mainly comprising isolated case reports that lacked rigor as none used quantitative or immunohistochemical approaches nor compared ET to control brains [131-137]. A popular disease model, initially proposed in the 1970s [138], attempted to link ET to an abnormal inferior olivary nucleus; however, empiric support for that model is limited $[57,139,140]$ and the model has recently fallen out of favor $[55,56]$. More recent research in the field has focused on the cerebellum, where there has been a reconceptualization of the disease as one of cerebellar degeneration, as will be discussed below [29, 35, 37-47].

The neuropathology of ET has been reviewed in detail elsewhere [32, 47, 127, 128]; hence, selective comments will be made here. Studies over the past fifteen years have systematically identified a broad range of structural, degenerative changes in the ET cerebellum, spanning across all Purkinje cell compartments [47, 127, 128]. In the dendritic compartment, studies show an increase in number of Purkinje cell dendritic swellings [141], pruning of the dendritic arbor [142], and a reduction in spine density [142]. In the Purkinje cell somatic compartment, one sees a reduction in Purkinje cell linear density in some studies [143-145], an increase in empty basket cell processes (i.e., a marker of Purkinje cell loss) [146], and an increase in the number of heterotopically-positioned Purkinje cell soma $[147,148]$. In the Purkinje cell axonal compartment, numerous changes in morphology have 
been observed, including an increase in the number of thickened axonal profiles, torpedoes, axonal recurrent collaterals, axonal branching, and terminal axonal sprouting $[45,149]$. Additional changes, possibly due to secondary remodeling, have been observed in neighboring neuronal populations. These changes include a hypertrophy of basket cell axonal processes $[150,151]$ and changes in the distribution of climbing fiberPurkinje cell synapses $[45,152,153]$. In carefully controlled studies, these changes all distinguish ET from normal control brains [45, 47]. Initial studies further indicate that the profile (i.e., constellation) of these changes may separate ET from other diseases of cerebellar degeneration, thereby serving as a preliminary disease signature, although these studies are in their infancy [32, $45,47]$.

In the majority of ET cases, other than a subset of ET cases with Lewy bodies [144, 154], the postmortem changes that have been observed to date are exclusively in the cerebellum. Furthermore, the inferior olivary nucleus has appeared normal in postmortem studies, which echoes data from neuroimaging and clinical studies, which suggest that structural changes in this nucleus do not play a role in tremor generation in $\operatorname{ET}[55,57,125$, 139, 140].

\section{ET as a Degenerative Disease - Review of the Data}

There is growing support for the notion that ET is a neurodegenerative disease $[29,37-51]$. Historically, the notion that ET could be neurodegenerative is not one that is new. As far back as 1948, Critchley and Greenfield wrote: "Although anatomical proof is as yet lacking, there are at least a number of clinical points to make question whether "essential tremor" may not, at times any rate, represent an incomplete or a premature variant of one of the cerebellar atrophies" [155]. Although not elaborated upon by those authors, these "clinical points" include the insidious onset of the disease, its association with advanced aging in the sense that both incidence and prevalence increase with aging exponentially, its gradual yet progressive nature, and the presence of numerous "cerebellar" features on neurological examination (e.g., intention tremor and ataxia, as discussed above). We will now elaborate on these and several additional points.

As is the case with other degenerative conditions such as Parkinson's disease, SCA, or dementia, the onset of ET is similarly insidious, as has been well-documented $[156,157]$. Indeed, age of onset can be difficult to determine because patients can have difficulty appreciating their tremor early on. Retrospectively recalling the point of onset can be similarly challenging, as tremor starts as one that is subtle, of low-amplitude, and difficult to distinguish from medication-induced tremor, anxiety- related tremor or other para-normal and/or situational forms of tremor [158-160]. As with other forms of neurodegeneration, the worsening of tremor in ET then follows a gradual yet progressive clinical course [161-163], albeit the pattern of progression differs across patients; there have never been any documented cases of reversion of tremor or cessation of disease once set in motion [39]. There is a marked and continued rise in disease occurrence (both incidence and prevalence), which is exponential in advanced ages [22, 58, 164-167], and which is yet another feature of the neurodegenerative conditions. Furthermore, ET itself has been associated with other neurodegenerative disorders. For example, there is a longstanding association between ET and PD [168-170]; indeed, having ET increases the risk of developing incident PD four to five-fold [171]. Furthermore, having older onset ET increases the risk of developing incident Alzheimer's disease nearly two-fold [172, 173]. Similarly, a possible association between ET and another tauopathy, progressive supranuclear palsy, has been reported [174]. This association between ET and subsequent development of these neurodegenerative diseases suggests that ET could share pathogenic mechanisms with some of these disorders. Although not studied extensively, other features of neurodegenerative diseases (e.g., an olfactory deficit, increased risk of mortality) have also been associated with ET in a small yet relevant literature [40, $48,175]$.

Neurodegenerative diseases have traditionally been characterized by the presence of selective involvement of anatomically and physiologically related systems of neurons, and neuronal loss is also considered by many to be a prominent feature of these diseases [40]. As seen in the degenerative ataxias, Purkinje cell loss has been noted in numerous studies of ET, with the extent of Purkinje cell loss being greater than seen in some forms of degenerative ataxia such as spinocerebellar ataxia $3[45$, 143-145]. In addition, as noted above, a host of other changes occur in the ET cerebellum, some of which are likely to be primary and degenerative, albeit many are on the milder end of the spectrum compared to other forms of SCA $[45,47]$.

As noted above, neurodegenerative diseases traditionally have been defined as diseases that begin insidiously and pursue a gradually progressive course that may continue for many years. Furthermore, their occurrence often increases markedly with advancing age. These and other clinical features, as well as postmortem features as reviewed above, suggest that ET is neurodegenerative. While many of these features in isolation are not specific to neurodegenerative diseases, the constellation of findings, all present in the same disease, is compelling. For a detailed review of these and other features, see Table 4 in Louis [40]. 


\section{Cumulative thesis: ET is the most common form of cerebellar degeneration}

Given that [1] ET is highly prevalent, [2] clinical, neuroimaging and postmortem studies have linked ET to the cerebellum, and [3] clinical and postmortem features suggest that it is neurodegenerative, then one would conjecture that it might be the most common form of cerebellar degeneration. Before reaching this conclusion, we must compare the prevalence of ET with that of other cerebellar degenerations.

As noted above, the SCAs as a composite whole are characterized by modest prevalence [8, 9]. For example, the prevalence of the autosomal dominant SCAs has been estimated to be 1 - 9 cases per 100000 people [8-15]. Autosomal recessive ataxias are similarly characterized by low prevalence; Friedreich's ataxia, the most common, has a prevalence of $0.5-5 / 100,000[13,16,17]$. Acquired degenerative ataxias are similarly rare: multiple system atrophy $(3.4-4.3 / 100,000)[18,19]$, paraneoplastic cerebellar degeneration $(1.2 / 100,000)$ [20], and ataxia with vitamin $\mathrm{E}$ deficiency $(0.06 / 100,000)$ [21].

As noted above, the prevalence of ET among all ages is $0.4 \%-0.9 \%$ (i.e., $400-900$ per 100,000 ) [22]. The prevalence of all other forms of cerebellar degeneration, combined, is approximately 20 per 100,000, which would mean that ET is 20 to 45 times more prevalent than all other forms of cerebellar degeneration combined.

\section{Caveats}

In this article, we make the argument that ET is the most common form of cerebellar degeneration. We are not making the claim that ET is always the result of cerebellar degeneration. ET is likely a family of diseases rather than a single entity [176]. Cerebellar degeneration can result in ET but other pathophysiological mechanisms are possible and are likely. Thus, as noted above, in a subset of ET cases (8 of 33 in one reported series), the main pathology was brainstem Lewy bodies [144, 154], and in a recent report, the spectrum of observable pathology in the cerebellum in a small proportion of ET cases overlapped with that seen in controls [45]. Whether degeneration may be present in other cerebellar outflow pathways in some ET cases remains to be explored. But even with the caveat that ET is likely not always the result of cerebellar degeneration, in the majority of cases, this is what is found on postmortem studies.

\section{Conclusions}

The degenerative cerebellar ataxias comprise a heterogeneous group of disorders whose hallmark clinical feature is ataxia, and this is accompanied, to variable degrees, by additional clinical features that are referable to cerebellar dysfunction [1-6]. ET is an exceptionally common neurological disease [22] whose primary motor feature is action tremor [23], although patients often manifest intention tremor [24-26], mild gait ataxia [27] and other features of cerebellar dysfunction [28]. In this paper, we review the abundant evidence derived from clinical, neuroimaging and postmortem studies, linking ET to cerebellar dysfunction. Furthermore, we review the combination of clinical, natural history and postmortem features that suggest that ET is neurodegenerative. We then compared the prevalence of ET to the other cerebellar degenerations and conclude that ET is 20 to 45 times more prevalent than all other forms of cerebellar degeneration combined. Given these data, it is logical to conclude that ET is, by far, the most common form of cerebellar degeneration.

Disease burden and public health impact are not solely a function of disease prevalence. ET is generally less devastating and is milder than most other forms of cerebellar degeneration, many although not all of which are associated with substantial reductions in life expectancy; nonetheless, tremor in advanced ET cases is severe and debilitating [177-179], ET is associated with a poorlyunderstood dementia [89], and in the limited literature, it is characterized by a modest increase in risk of mortality $[175,180]$. Hence from multiple perspectives (i.e., disease prevalence, disease burden) the public health impact of ET is substantial.

Abbreviations

ET: Essential tremor; MR: Magnetic resonance; PET: Positron emission tomography; SCA: Spinocerebellar ataxia

\section{Acknowledgements \\ None}

Authors' contributions

Dr. Louis (Conception and preparation of first draft). Dr. Faust (Conception and edits to first draft). The author(s) read and approved the final manuscript.

\section{Funding}

Drs. Louis and Faust acknowledge funding from National Institutes of Health R01 NS088257. The funder did not play any role in the writing of this manuscript.

\section{Availability of data and materials}

This is a review paper and this is not applicable.

Ethics approval and consent to participate

This is a review paper. Therefore, this is not applicable.

\section{Consent for publication}

This is not applicable.

Competing interests

Dr. Louis and Dr. Faust declare that they have no competing interests.

\section{Author details}

'Department of Neurology and Therapeutics, University of Texas

Southwestern, Dallas, TX, USA. ²Department of Pathology and Cell Biology, Columbia University Irving Medical Center and the New York Presbyterian Hospital, New York, NY, USA. 
Received: 17 June 2020 Accepted: 3 August 2020

\section{Published online: 14 August 2020}

\section{References}

1. Paulson HL. The spinocerebellar ataxias. J Neuroophthalmol. 2009;29(3):22737.

2. Koeppen $\mathrm{AH}$. The neuropathology of the adult cerebellum. Handb Clin Neurol. 2018;154:129-49.

3. Manto M, Gandini J, Feil K, Strupp M. Cerebellar ataxias: an update. Curr Opin Neurol. 2020;33(1):150-60.

4. Meira AT, Arruda WO, Ono SE, Neto AC, Raskin S, Camargo CHF, et al. Neuroradiological Findings in the Spinocerebellar Ataxias. Tremor Other Hyperkinet Mov (N Y). 2019;9:10.7916/tohm.v0.682.

5. Soong BW, Morrison PJ. Spinocerebellar ataxias. Handb Clin Neurol. 2018; 155:143-74.

6. Huang M, Verbeek DS. Why do so many genetic insults lead to Purkinje Cell degeneration and spinocerebellar ataxia? Neurosci Lett. 2019;688:49-57.

7. Salman MS. Epidemiology of Cerebellar Diseases and Therapeutic Approaches. Cerebellum. 2018;17(1):4-11.

8. Zortea M, Armani M, Pastorello E, Nunez GF, Lombardi S, Tonello S, et al. Prevalence of inherited ataxias in the province of Padua. Italy Neuroepidemiology. 2004;23(6):275-80.

9. Muzaimi MB, Thomas J, Palmer-Smith S, Rosser L, Harper PS, Wiles CM, et al. Population based study of late onset cerebellar ataxia in south east Wales. J Neurol Neurosurg Psychiatry. 2004;75(8):1129-34.

10. Sura T, Eu-Ahsunthornwattana J, Youngcharoen S, Busabaratana M, Dejsuphong D, Trachoo O, et al. Frequencies of spinocerebellar ataxia subtypes in Thailand: window to the population history? J Hum Genet. 2009;54(5):284-8.

11. Velazquez-Perez L, Medrano-Montero J, Rodriguez-Labrada R, CanalesOchoa N, Campins Ali J, Carrillo Rodes FJ, et al. Hereditary Ataxias in Cuba: A Nationwide Epidemiological and Clinical Study in 1001 Patients. Cerebellum. 2020;19(2):252-64.

12. Hellberg C, Alinder E, Jaraj D, Puschmann A. Nationwide prevalence of primary dystonia, progressive ataxia and hereditary spastic paraplegia. Parkinsonism Relat Disord. 2019;69:79-84.

13. Ruano L, Melo C, Silva MC, Coutinho P. The global epidemiology of hereditary ataxia and spastic paraplegia: a systematic review of prevalence studies. Neuroepidemiology. 2014;42(3):174-83.

14. van de Warrenburg BP, Sinke RJ, Verschuuren-Bemelmans CC, Scheffer $H$, Brunt ER, Ippel PF, et al. Spinocerebellar ataxias in the Netherlands: prevalence and age at onset variance analysis. Neurology. 2002;58(5):702-8.

15. Kim JS, Cho JW. Hereditary Cerebellar Ataxias: A Korean Perspective. J Mov Disord. 2015:8(2):67-75.

16. Lopez-Arlandis JM, Vilchez JJ, Palau F, Sevilla T. Friedreich's ataxia: an epidemiological study in Valencia, Spain, based on consanguinity analysis. Neuroepidemiology. 1995;14(1):14-9.

17. Wedding IM, Kroken M, Henriksen SP, Selmer KK, Fiskerstrand T, Knappskog PM, et al. Friedreich ataxia in Norway - an epidemiological, molecular and clinical study. Orphanet J Rare Dis. 2015;10:108.

18. Fleury V, Brindel P, Nicastro N, Burkhard PR. Descriptive epidemiology of parkinsonism in the Canton of Geneva, Switzerland. Parkinsonism Relat Disord. 2018:54:30-9.

19. Bjornsdottir A, Gudmundsson G, Blondal H, Olafsson E. Incidence and prevalence of multiple system atrophy: a nationwide study in Iceland. J Neurol Neurosurg Psychiatry. 2013;84(2):136-40.

20. Vogrig A, Gigli GL, Segatti S, Corazza E, Marini A, Bernardini A, et al. Epidemiology of paraneoplastic neurological syndromes: a populationbased study. J Neurol. 2020;267(1):26-35.

21. Elkamil A, Johansen KK, Aasly J. Ataxia with vitamin e deficiency in norway. J Mov Disord. 2015;8(1):33-6.

22. Louis ED, Ferreira JJ. How common is the most common adult movement disorder? Update on the worldwide prevalence of essential tremor. Mov Disord. 2010;25(5):534-41.

23. Louis ED. The primary type of tremor in essential tremor is kinetic rather than postural: cross-sectional observation of tremor phenomenology in 369 cases. Eur J Neurol. 2013;20(4):725-7.

24. Louis ED, Frucht SJ, Rios E. Intention tremor in essential tremor: Prevalence and association with disease duration. Mov Disord. 2009;24(4):626-7.

25. Louis ED. Twelve clinical pearls to help distinguish essential tremor from other tremors. Expert Rev Neurother. 2014;14(9):1057-65.
26. Louis ED. Essential tremor: a nuanced approach to the clinical features. Pract Neurol. 2019;19(5):389-98

27. Rao AK, Louis ED. Ataxic Gait in Essential Tremor: A Disease-Associated Feature? Tremor Other Hyperkinet Mov (N Y). 2019;9:10.7916/d8-28jq-8t52.

28. Benito-Leon J, Labiano-Fontcuberta A. Linking Essential Tremor to the Cerebellum: Clinical Evidence. Cerebellum. 2016;15(3):253-62.

29. Grimaldi G, Manto M. Is essential tremor a Purkinjopathy? The role of the cerebellar cortex in its pathogenesis. Mov Disord. 2013;28(13):1759-61.

30. Cerasa A, Quattrone A. Linking Essential Tremor to the CerebellumNeuroimaging Evidence. Cerebellum. 2016;15(3):263-75.

31. Marin-Lahoz J, Gironell A. Linking Essential Tremor to the Cerebellum: Neurochemical Evidence. Cerebellum. 2016;15(3):243-52

32. Louis ED. Linking Essential Tremor to the Cerebellum: Neuropathological Evidence. Cerebellum. 2016;15(3):235-42.

33. Maas R, Helmich RCG, van de Warrenburg BPC. The role of the cerebellum in degenerative ataxias and essential tremor: Insights from noninvasive modulation of cerebellar activity. Mov Disord. 2020;35(2):215-27.

34. Mavroudis I, Petridis F, Kazis D. Neuroimaging and neuropathological findings in essential tremor. Acta Neurol Scand. 2019;139(6):491-6.

35. Louis ED. De Sedibus et Causis Morborum: is Essential Tremor a Primary Disease of the Cerebellum? Cerebellum. 2016;15(3):233-4.

36. Louis ED. Essential tremor and the cerebellum. Handb Clin Neurol. 2018;155: $245-58$

37. Benito-Leon J. Essential tremor: a neurodegenerative disease? Tremor Other Hyperkinet Mov (N Y). 2014;4:252.

38. Bermejo-Pareja F. Essential tremor--a neurodegenerative disorder associated with cognitive defects? Nat Rev Neurol. 2011;7(5):273-82.

39. Bonuccelli U. Essential tremor is a neurodegenerative disease. J Neural Transm. 2012;119(11):1383-7.

40. Louis ED. Essential tremors: a family of neurodegenerative disorders? Arch Neurol. 2009;66(10):1202-8.

41. Samson M, Claassen DO. Neurodegeneration and the Cerebellum. Neurodegener Dis. 2017;17(4-5):155-65

42. Boutin E, Vaugoyeau M, Eusebio A, Azulay JP, Witjas T. News and controversies regarding essential tremor. Rev Neurol (Paris). 2015;171(5):41525.

43. Tak AZA, Sengul Y, Karadag AS. Evaluation of thickness of retinal nerve fiber layer, ganglion cell layer, and choroidal thickness in essential tremor: can eyes be a clue for neurodegeneration? Acta Neurol Belg. 2018;118(2):23541.

44. Gironell A. The GABA Hypothesis in Essential Tremor: Lights and Shadows. Tremor Other Hyperkinet Mov (N Y). 2014:4:254.

45. Louis ED, Kerridge CA, Chatterjee D, Martuscello RT, Diaz DT, Koeppen AH, et al. Contextualizing the pathology in the essential tremor cerebellar cortex: a patholog-omics approach. Acta Neuropathol. 2019;138(5):859-76.

46. Louis ED. Re-thinking the biology of essential tremor: from models to morphology. Parkinsonism Relat Disord. 2014;20(Suppl 1):S88-93.

47. Louis ED, Faust PL. Essential tremor pathology: neurodegeneration and reorganization of neuronal connections. Nat Rev Neurol. 2020;16(2):69-83.

48. Altunisik E, Baykan AH. Comparison of the Olfactory Bulb Volume and the Olfactory Tract Length Between Patients Diagnosed with Essential Tremor and Healthy Controls: Findings in Favor of Neurodegeneration. Cureus. 2019:11(10):e5846.

49. Prasad S, Shah A, Bhalsing KS, Ingalhalikar M, Saini J, Pal PK. Clinical correlates of abnormal subcortical volumes in Essential Tremor. J Neural Transm (Vienna). 2019;126(5):569-76.

50. Caligiuri ME, Arabia G, Barbagallo G, Lupo A, Morelli M, Nistico R, et al. Structural connectivity differences in essential tremor with and without resting tremor. J Neurol. 2017;264(9):1865-74.

51. Novellino F, Nicoletti G, Cherubini A, Caligiuri ME, Nistico R, Salsone M, et al. Cerebellar involvement in essential tremor with and without resting tremor: A Diffusion Tensor Imaging study. Parkinsonism Relat Disord. 2016;27:61-6.

52. Filip P, Lungu OV, Manto MU, Bares M. Linking Essential Tremor to the Cerebellum: Physiological Evidence. Cerebellum. 2016;15(6):774-80.

53. Handforth A. Linking Essential Tremor to the Cerebellum-Animal Model Evidence. Cerebellum. 2016;15(3):285-98.

54. Louis ED, Ottman R. How many people in the USA have essential tremor? Deriving a population estimate based on epidemiological data. Tremor Other Hyperkinet Mov (N Y). 2014;4:259.

55. Louis ED, Lenka A. The Olivary Hypothesis of Essential Tremor: Time to Lay this Model to Rest? Tremor Other Hyperkinet Mov (N Y). 2017;7:473. 
56. Hopfner F, Haubenberger D, Galpern WR, Gwinn K, Van't Veer A, White S, et al. Knowledge gaps and research recommendations for essential tremor. Parkinsonism Relat Disord. 2016;33:27-35.

57. Elkouzi A, Kattah JC, Elble RJ. Hypertrophic Olivary Degeneration Does Not Reduce Essential Tremor. Mov Disord Clin Pract. 2016;3(2):209-11.

58. Louis ED, Thawani SP, Andrews HF. Prevalence of essential tremor in a multiethnic, community-based study in northern Manhattan, New York, N.Y. Neuroepidemiology. 2009;32(3):208-14.

59. Deuschl G, Wenzelburger R, Loffler K, Raethjen J, Stolze H. Essential tremor and cerebellar dysfunction clinical and kinematic analysis of intention tremor. Brain. 2000;123(Pt 8):1568-80.

60. Sternberg EJ, Alcalay RN, Levy OA, Louis ED. Postural and Intention Tremors: A Detailed Clinical Study of Essential Tremor vs. Parkinson's Disease Front Neurol. 2013:4:51.

61. Leegwater-Kim J, Louis ED, Pullman SL, Floyd AG, Borden S, Moskowitz CB, et al. Intention tremor of the head in patients with essential tremor. Mov Disord. 2006;21(11):2001-5.

62. Kestenbaum M, Michalec M, Yu Q, Pullman SL, Louis ED. Intention Tremor of the Legs in Essential Tremor: Prevalence and Clinical Correlates. Mov Disord Clin Pract. 2015;2(1):24-8.

63. Louis ED, Rios E, Rao AK. Tandem gait performance in essential tremor: clinical correlates and association with midline tremors. Mov Disord. 2010; 25(11):1633-8.

64. Singer C, Sanchez-Ramos J, Weiner WJ. Gait abnormality in essential tremor. Mov Disord. 1994;9(2):193-6.

65. Hubble JP, Busenbark KL, Pahwa R, Lyons K, Koller WC. Clinical expression of essential tremor: effects of gender and age. Mov Disord. 1997;12(6):969-72.

66. Stolze H, Petersen G, Raethjen J, Wenzelburger R, Deuschl G. The gait disorder of advanced essential tremor. Brain. 2001;124(Pt 11):2278-86.

67. Kronenbuerger M, Konczak J, Ziegler W, Buderath P, Frank B, Coenen VA, et al. Balance and motor speech impairment in essential tremor. Cerebellum. 2009:8(3):389-98

68. Parisi SL, Heroux ME, Culham EG, Norman KE. Functional mobility and postural control in essential tremor. Arch Phys Med Rehabil. 2006;87(10): 1357-64.

69. Rao AK, Gilman A, Louis ED. Balance confidence and falls in nondemented essential tremor patients: the role of cognition. Arch Phys Med Rehabil. 2014:95(10):1832-7.

70. Hoskovcova M, Ulmanova O, Sprdlik O, Sieger T, Novakova J, Jech R, et al. Disorders of Balance and Gait in Essential Tremor Are Associated with Midline Tremor and Age. Cerebellum. 2013;12(1):27-34.

71. Louis ED, Galecki M, Rao AK. Four Essential Tremor Cases with Moderately Impaired Gait: How Impaired can Gait be in this Disease? Tremor Other Hyperkinet Mov (N Y). 2013;3:tre-03-200-4597-1.

72. Rao AK, Gillman A, Louis ED. Quantitative gait analysis in essential tremor reveals impairments that are maintained into advanced age. Gait Posture. 2011;34(1):65-70.

73. Palliyath S, Hallett M, Thomas SL, Lebiedowska MK. Gait in patients with cerebellar ataxia. Mov Disord. 1998;13(6):958-64.

74. Stolze H, Klebe S, Petersen G, Raethjen J, Wenzelburger R, Witt K, et al. Typical features of cerebellar ataxic gait. J Neurol Neurosurg Psychiatry. 2002;73(3):310-2

75. Morton SM, Bastian AJ. Cerebellar control of balance and locomotion. Neuroscientist. 2004;10(3):247-59.

76. Helmchen C, Hagenow A, Miesner J, Sprenger A, Rambold H, Wenzelburger $\mathrm{R}$, et al. Eye movement abnormalities in essential tremor may indicate cerebellar dysfunction. Brain. 2003;126(Pt 6):1319-32.

77. Gitchel GT, Wetzel PA, Baron MS. Slowed saccades and increased square wave jerks in essential tremor. Tremor Other Hyperkinet Mov (N Y). 2013;3: tre-03-178-4416-2

78. Wojcik-Pedziwiatr M, Plinta K, Krzak-Kubica A, Zajdel K, Falkiewicz M, Dylak J, et al. Eye movement abnormalities in essential tremor. J Hum Kinet. 2016; 52:53-64.

79. Bares M, Husarova I, Lungu OV. Essential tremor, the cerebellum, and motor timing: towards integrating them into one complex entity. Tremor Other Hyperkinet Mov (N Y). 2012;2:tre-02-93-653-1.

80. Farkas Z, Szirmai I, Kamondi A. Impaired rhythm generation in essential tremor. Mov Disord. 2006;21(8):1196-9.

81. Trillenberg P, Fuhrer J, Sprenger A, Hagenow A, Kompf D, Wenzelburger R, et al. Eye-hand coordination in essential tremor. Mov Disord. 2006;21(3): 373-9.
82. Avanzino L, Bove M, Tacchino A, Ruggeri P, Giannini A, Trompetto C, et al. Cerebellar involvement in timing accuracy of rhythmic finger movements in essential tremor. Eur J Neurosci. 2009;30(10):1971-9.

83. Bares M, Lungu OV, Husarova I, Gescheidt T. Predictive motor timing performance dissociates between early diseases of the cerebellum and Parkinson's disease. Cerebellum. 2010;9(1):124-35.

84. Bares M, Apps R, Avanzino L, Breska A, D'Angelo E, Filip P, et al. Consensus paper: Decoding the Contributions of the Cerebellum as a Time Machine. From Neurons to Clinical Applications. Cerebellum. 2019;18(2):266-86.

85. Lawrenson C, Bares M, Kamondi A, Kovacs A, Lumb B, Apps R, et al. The mystery of the cerebellum: clues from experimental and clinical observations. Cerebellum Ataxias. 2018;5:8.

86. Kronenbuerger $\mathrm{M}$, Gerwig M, Brol B, Block F, Timmann D. Eyeblink conditioning is impaired in subjects with essential tremor. Brain. 2007;130(Pt 6):1538-51.

87. Shill HA, De La Vega FJ, Samanta J, Stacy M. Motor learning in essential tremor. Mov Disord. 2009;24(6):926-8.

88. Louis ED. Non-motor symptoms in essential tremor: A review of the current data and state of the field. Parkinsonism Relat Disord. 2016;22(Suppl 1(0 1)): S115-8.

89. Louis ED, Joyce $J$, Cosentino S. Mind the gaps: What we don't know about cognitive impairment in essential tremor. Parkinsonism Relat Disord. 2019; 63:10-9.

90. Farrell K, Cosentino S, lida MA, Chapman S, Bennett DA, Faust PL, et al. Quantitative Assessment of Pathological Tau Burden in Essential Tremor: A Postmortem Study. J Neuropathol Exp Neurol. 2019;78(1):31-7.

91. Pan JJ, Lee M, Honig LS, Vonsattel JP, Faust PL, Louis ED. Alzheimer's-related changes in non-demented essential tremor patients vs. controls: links between tau and tremor? Parkinsonism Relat Disord. 2014;20(6):655-8.

92. Janicki SC, Cosentino S, Louis ED. The cognitive side of essential tremor: what are the therapeutic implications? Ther Adv Neurol Disord. 2013;6(6): 353-68.

93. Dupuis MJ, Delwaide PJ, Boucquey D, Gonsette RE. Homolateral disappearance of essential tremor after cerebellar stroke. Mov Disord. 1989; $4(2): 183-7$.

94. Louis ED, Huang CC, Dyke JP, Long Z, Dydak U. Neuroimaging studies of essential tremor: how well do these studies support/refute the neurodegenerative hypothesis? Tremor Other Hyperkinet Mov (N Y). 2014;4: 235.

95. Lenka A, Bhalsing KS, Panda R, Jhunjhunwala K, Naduthota RM, Saini J, et al. Role of altered cerebello-thalamo-cortical network in the neurobiology of essential tremor. Neuroradiology. 2017;59(2):157-68.

96. Sharifi S, Nederveen AJ, Booij J, van Rootselaar AF. Neuroimaging essentials in essential tremor: a systematic review. Neuroimage Clin. 2014:5:217-31.

97. Daniels C, Peller M, Wolff S, Alfke K, Witt K, Gaser C, et al. Voxel-based morphometry shows no decreases in cerebellar gray matter volume in essential tremor. Neurology. 2006;67(8):1452-6.

98. Quattrone A, Cerasa A, Messina D, Nicoletti G, Hagberg GE, Lemieux L, et al. Essential head tremor is associated with cerebellar vermis atrophy: a volumetric and voxel-based morphometry MR imaging study. AJNR Am J Neuroradiol. 2008;29(9):1692-7.

99. Cerasa A, Messina D, Nicoletti G, Novellino F, Lanza P, Condino F, et al. Cerebellar Atrophy in Essential Tremor Using an Automated Segmentation Method. AJNR Am J Neuroradiol. 2009;30(6):1240-3.

100. Benito-Leon J, Alvarez-Linera J, Hernandez-Tamames JA, Alonso-Navarro $\mathrm{H}$, Jimenez-Jimenez FJ, Louis ED. Brain structural changes in essential tremor: Voxel-based morphometry at 3-Tesla. J Neurol Sci. 2009;287(1-2): $138-42$

101. Bagepally BS, Bhatt MD, Chandran V, Saini J, Bharath RD, Vasudev MK, et al. Decrease in cerebral and cerebellar gray matter in essential tremor: a voxelbased morphometric analysis under 3T MRI. J Neuroimaging. 2012;22(3): 275-8.

102. Lin CH, Chen CM, Lu MK, Tsai CH, Chiou JC, Liao JR, et al. VBM Reveals Brain Volume Differences between Parkinson's Disease and Essential Tremor Patients. Front Hum Neurosci. 2013;7:247.

103. Dyke JP, Cameron E, Hernandez N, Dydak U, Louis ED. Gray matter density loss in essential tremor: a lobule by lobule analysis of the cerebellum. Cerebellum Ataxias. 2017:4:10.

104. Pagan FL, Butman JA, Dambrosia JM, Hallett M. Evaluation of essential tremor with multi-voxel magnetic resonance spectroscopy. Neurology. 2003; 60(8):1344-7. 
105. Louis ED, Shungu DC, Chan S, Mao X, Jurewicz EC, Watner D. Metabolic abnormality in the cerebellum in patients with essential tremor: a proton magnetic resonance spectroscopic imaging study. Neurosci Lett. 2002; 333(1):17-20.

106. Shin DH, Han BS, Kim HS, Lee PH. Diffusion tensor imaging in patients with essential tremor. AJNR Am J Neuroradiol. 2008;29(1):151-3.

107. Martinelli P, Rizzo G, Manners D, Tonon C, Pizza F, Testa C, et al. Diffusionweighted imaging study of patients with essential tremor. Mov Disord. 2007;22(8):1182-5.

108. Buijink AW, Caan MW, Tijssen MA, Hoogduin JM, Maurits NM, van Rootselaar AF. Decreased cerebellar fiber density in cortical myoclonic tremor but not in essential tremor. Cerebellum. 2013;12(2):199-204.

109. Nicoletti G, Manners D, Novellino F, Condino F, Malucelli E, Barbiroli B, et al. Diffusion tensor MRI changes in cerebellar structures of patients with familial essential tremor. Neurology. 74(12):988-94.

110. Jia L, Jia-Lin S, Qin D, Qing L, Yan Z. A diffusion tensor imaging study in essential tremor. J Neuroimaging. 2011;21(4):370-4

111. Saini J, Bagepally BS, Bhatt MD, Chandran V, Bharath RD, Prasad C, et al. Diffusion tensor imaging: tract based spatial statistics study in essential tremor. Parkinsonism Relat Disord. 2012;18(5):477-82.

112. Klein JC, Lorenz B, Kang JS, Baudrexel S, Seifried C, van de Loo S, et al. Diffusion tensor imaging of white matter involvement in essential tremor. Hum Brain Mapp. 2011;32(6):896-904.

113. Fang W, Lv F, Luo T, Cheng O, Liao W, Sheng K, et al. Abnormal regional homogeneity in patients with essential tremor revealed by resting-state functional MRI. PLoS One. 2013;8(7):e69199.

114. Bucher SF, Seelos KC, Dodel RC, Reiser M, Oertel WH. Activation mapping in essential tremor with functional magnetic resonance imaging. Ann Neurol. 1997:41(1):32-40.

115. Passamonti L, Novellino F, Cerasa A, Chiriaco C, Rocca F, Matina MS, et al. Altered cortical-cerebellar circuits during verbal working memory in essential tremor. Brain. 134(Pt 8):2274-86.

116. Cerasa A, Passamonti L, Novellino F, Salsone M, Gioia MC, Morelli M, et al. Fronto-parietal overactivation in patients with essential tremor during Stroop task. Neuroreport. 2010;21(2):148-51.

117. Popa T, Russo M, Vidailhet M, Roze E, Lehericy S, Bonnet C, et al. Cerebellar rTMS stimulation may induce prolonged clinical benefits in essential tremor, and subjacent changes in functional connectivity: an open label trial. Brain Stimul. 2013;6(2):175-9.

118. Wang L, Lei D, Suo X, Li N, Lu Z, Li J, et al. Resting-state fMRI study on drugnaive patients of essential tremor with and without head tremor. Sci Rep. 2018;8(1):10580.

119. Gallea C, Popa T, Garcia-Lorenzo D, Valabregue R, Legrand AP, Marais L, et al. Intrinsic signature of essential tremor in the cerebello-frontal network. Brain. 2015;138(Pt 10):2920-33.

120. Boecker H, Wills AJ, Ceballos-Baumann A, Samuel M, Thompson PD, Findley $\sqcup$, et al. The effect of ethanol on alcohol-responsive essential tremor: a positron emission tomography study. Ann Neurol. 1996;39(5):650-8.

121. Colebatch JG, Findley LJ, Frackowiak RS, Marsden CD, Brooks DJ. Preliminary report: activation of the cerebellum in essential tremor. Lancet. 1990; 336(8722):1028-30.

122. Jenkins $\mathbb{H}_{\text {, Bain } P G}$, Colebatch JG, Thompson PD, Findley LJ, Frackowiak RS, et al. A positron emission tomography study of essential tremor: evidence for overactivity of cerebellar connections. Ann Neurol. 1993;34(1):82-90.

123. Hallett M, Dubinsky RM. Glucose metabolism in the brain of patients with essential tremor. J Neurol Sci. 1993;114(1):45-8.

124. Wills AJ, Jenkins $I H$, Thompson PD, Findley LJ, Brooks DJ. A positron emission tomography study of cerebral activation associated with essential and writing tremor. Arch Neurol. 1995;52(3):299-305.

125. Wills AJ, Jenkins $\mid H$, Thompson PD, Findley LJ, Brooks DJ. Red nuclear and cerebellar but no olivary activation associated with essential tremor: a positron emission tomographic study. Ann Neurol. 1994;36(4):636-42.

126. Boecker H, Weindl A, Brooks DJ, Ceballos-Baumann AO, Liedtke C, Miederer $M$, et al. GABAergic dysfunction in essential tremor: an 11C-flumazenil PET study. J Nucl Med. 51(7):1030-5

127. Louis ED. Essential tremor: from bedside to bench and back to bedside. Curr Opin Neurol. 2014;27(4):461-7.

128. Louis ED. From Neurons to Neuron Neighborhoods: the Rewiring of the Cerebellar Cortex in Essential Tremor. Cerebellum. 2014;13(4):501-2.

129. Louis ED, Vonsattel JP, Honig LS, Ross GW, Lyons KE, Pahwa R. Neuropathologic findings in essential tremor. Neurology. 2006;66(11):1756-9.
130. Louis ED, Vonsattel JP. The emerging neuropathology of essential tremor. Mov Disord. 2007;23(2):174-82

131. Bergamasco I. Intorno ad un caso di tremore essenziale simulant in parte il quadro della sclerosi multipla. Riv Pat Nerv Ment. 1907:115:80-90.

132. Hassler R. Zur pathologischen anatomie des senilen und des parkinsonistischen Tremor. J Psychol Neurol. 1939;49:193-230.

133. Frankl-Hochwart L. Universitat Wien Neurologisches Institute Arbeiten aus dem Neurologischen Institute. Franz Deuticke; Leipzig: 1903. Zur kenntnis der Pseudosklerose (Westphal-Strumpell); 1903. p. 1-47.

134. Mylle G, Van Bogaert L. Etudes anatomo-cliniques de syndromes hypercinetiques complexes. I. sur le tremblement familial. Mschr Psychiatr Neurol. 1940;103:28-43.

135. Mylle G, Van Bogaert L. Du tremblement essentiel non familial. Monatsschr Psychiatr Neurol. 1948;115:80-90.

136. Herskovits E, Blackwood W. Essential (familial, hereditary) tremor: a case report. J Neurol Neurosurg Psychiatry. 1969;32(6):509-11.

137. Lapresle J, Rondot P, Said G. Tremblement idopathique de repos, d'attitude et d'action. Etude anatomo-clinique d'une observation. Rev Neurol. 1974; 130:343-8.

138. Llinas R, Volkind RA. The olivo-cerebellar system: functional properties as revealed by harmaline-induced tremor. Exp Brain Res. 1973;18(1):69-87.

139. Louis ED, Diaz DT, Kuo SH, Gan SR, Cortes EP, Vonsattel JPG, et al. Inferior Olivary nucleus degeneration does not lessen tremor in essential tremor. Cerebellum Ataxias. 2018;5:1.

140. Louis ED, Babij R, Cortes E, Vonsattel JP, Faust PL. The inferior olivary nucleus: A postmortem study of essential tremor cases versus controls. Mov Disord. 2013;28(6):779-86.

141. Yu M, Ma K, Faust PL, Honig LS, Cortes E, Vonsattel JP, et al. Increased number of Purkinje cell dendritic swellings in essential tremor. Eur J Neurol. 2012;19(4):625-30.

142. Louis ED, Lee M, Babij R, Ma K, Cortes E, Vonsattel JP, et al. Reduced Purkinje cell dendritic arborization and loss of dendritic spines in essential tremor. Brain. 2014;137(Pt 12):3142-8.

143. Axelrad JE, Louis ED, Honig LS, Flores I, Ross GW, Pahwa R, et al. Reduced purkinje cell number in essential tremor: a postmortem study. Arch Neurol. 2008:65(1):101-7.

144. Louis ED, Faust PL, Vonsattel JP, Honig LS, Rajput A, Robinson CA, et al. Neuropathological changes in essential tremor: 33 cases compared with 21 controls. Brain. 2007;130(Pt 12):3297-307.

145. Choe M, Cortes E, Vonsattel JP, Kuo SH, Faust PL, Louis ED. Purkinje cell loss in essential tremor: Random sampling quantification and nearest neighbor analysis. Mov Disord. 2016;31(3):393-401.

146. Lee PJ, Kerridge CA, Chatterjee D, Koeppen AH, Faust PL, Louis ED. A Quantitative Study of Empty Baskets in Essential Tremor and Other Motor Neurodegenerative Diseases. J Neuropathol Exp Neurol. 2019;78(2):113-22.

147. Louis ED, Kuo SH, Tate WJ, Kelly GC, Gutierrez J, Cortes EP, et al. Heterotopic Purkinje Cells: a Comparative Postmortem Study of Essential Tremor and Spinocerebellar Ataxias 1, 2, 3, and 6. Cerebellum. 2018;17(2):104-10.

148. Kuo SH, Erickson-Davis C, Gillman A, Faust PL, Vonsattel JP, Louis ED. Increased number of heterotopic Purkinje cells in essential tremor. J Neurol Neurosurg Psychiatry. 2011;82(9):1038-40.

149. Babij R, Lee M, Cortes E, Vonsattel JP, Faust PL, Louis ED. Purkinje cell axonal anatomy: quantifying morphometric changes in essential tremor versus control brains. Brain. 2013;136(Pt 10):3051-61.

150. Erickson-Davis CR, Faust PL, Vonsattel JP, Gupta S, Honig LS, Louis ED. "Hairy baskets" associated with degenerative Purkinje cell changes in essential tremor. J Neuropathol Exp Neurol. 2010;69(3):262-71.

151. Kuo SH, Tang G, Louis ED, Ma K, Babji R, Balatbat M, et al. Lingo-1 expression is increased in essential tremor cerebellum and is present in the basket cell pinceau. Acta Neuropathol. 2013;125(6):879-89.

152. Lin CY, Louis ED, Faust PL, Koeppen AH, Vonsattel JP, Kuo SH. Abnormal climbing fibre-Purkinje cell synaptic connections in the essential tremor cerebellum. Brain. 2014;137(Pt 12):3149-59.

153. Kuo SH, Lin CY, Wang J, Sims PA, Pan MK, Liou JY, et al. Climbing fiberPurkinje cell synaptic pathology in tremor and cerebellar degenerative diseases. Acta Neuropathol. 2017;133(1):121-38.

154. Louis ED, Honig LS, Vonsattel JP, Maraganore DM, Borden S, Moskowitz CB. Essential tremor associated with focal nonnigral Lewy bodies: a clinicopathologic study. Arch Neurol. 2005;62(6):1004-7.

155. Critchley M, Greenfield J.G. Olivo-pontocerebellar atrophy. Brain. 1948;71(Pt. 4):343-364. 
156. Larsson T, Sjogren T. Essential tremor: a clinical and genetic population study. Acta Psychiatr Scand Suppl. 1960;36(144):1-176.

157. Critchley M. Observations of essential (heredofamilial) tremor. Brain. 1949; 72(Pt.2):113-39.

158. Louis ED, Ford B, Pullman SL. Prevalence of asymptomatic tremor in relatives of patients with essential tremor. Arch Neurol. 1997;54(2):197-200.

159. Louis ED, Ottman R, Clark LN. Clinical classification of borderline cases in the family study of essential tremor: an analysis of phenotypic features. Tremor Other Hyperkinet Mov (N Y). 2014;4:220.

160. Louis ED. Age of onset: can we rely on essential tremor patients to report this? Data from a prospective, longitudinal study. Neuroepidemiology. 2013; 40(2):93-8.

161. Putzke JD, Whaley NR, Baba Y, Wszolek ZK, Uitti RJ. Essential tremor: predictors of disease progression in a clinical cohort. J Neurol Neurosurg Psychiatry. 2006;77(11):1235-7.

162. Louis ED, Ford B, Barnes LF. Clinical subtypes of essential tremor. Arch Neurol. 2000;57(8):1194-8.

163. Louis ED, Agnew A, Gillman A, Gerbin M, Viner AS. Estimating annual rate of decline: prospective, longitudinal data on arm tremor severity in two groups of essential tremor cases. J Neurol Neurosurg Psychiatry. 2011;82(7): $761-5$.

164. Dogu O, Sevim S, Camdeviren H, Sasmaz T, Bugdayci R, Aral M, et al. Prevalence of essential tremor: door-to-door neurologic exams in Mersin Province, Turkey. Neurology. 2003;61(12):1804-6.

165. Benito-Leon J, Bermejo-Pareja F, Louis ED. Incidence of essential tremor in three elderly populations of central Spain. Neurology. 2005;64(10):1721-5.

166. Louis ED. The Roles of Age and Aging in Essential Tremor: An Epidemiological Perspective. Neuroepidemiology. 2019;52(1-2):111-8.

167. Das SK, Banerjee TK, Roy T, Raut DK, Chaudhuri A, Hazra A. Prevalence of essential tremor in the city of Kolkata, India: a house-to-house survey. Eur $J$ Neurol. 2009;16(7):801-7.

168. LaRoia H, Louis ED. Association between essential tremor and other neurodegenerative diseases: what is the epidemiological evidence? Neuroepidemiology. 2011;37(1):1-10.

169. Tarakad A, Jankovic J. Essential Tremor and Parkinson's Disease: Exploring the Relationship. Tremor Other Hyperkinet Mov (N Y). 2018;8:589.

170. Thenganatt MA, Jankovic J. The relationship between essential tremor and Parkinson's disease. Parkinsonism Relat Disord. 2016;22(Suppl 1):S162-5.

171. Benito-Leon J, Louis ED, Bermejo-Pareja F. Risk of incident Parkinson's disease and parkinsonism in essential tremor: a population based study. J Neurol Neurosurg Psychiatry. 2009;80(4):423-5.

172. Thawani SP, Schupf N, Louis ED. Essential tremor is associated with dementia: prospective population-based study in New York. Neurology. 2009:73(8):621-5.

173. Bermejo-Pareja F, Louis ED, Benito-Leon J. Neurological Disorders in Central Spain Study G. Risk of incident dementia in essential tremor: a populationbased study. Mov Disord. 2007;22(11):1573-80.

174. Louis ED, Babij R, Ma K, Cortes E, Vonsattel JP. Essential tremor followed by progressive supranuclear palsy: postmortem reports of 11 patients. J Neuropathol Exp Neurol. 2013;72(1):8-17.

175. Louis ED, Benito-Leon J, Ottman R, Bermejo-Pareja F. A population-based study of mortality in essential tremor. Neurology. 2007;69(21):1982-9.

176. Louis ED. 'Essential Tremor' or 'the Essential Tremors': Is This One Disease or a Family of Diseases? Neuroepidemiology. 2014;42(2):81-9.

177. Louis ED, Gerbin M, Galecki M. Essential tremor 10, 20, 30, 40: clinical snapshots of the disease by decade of duration. Eur J Neurol. 2013;20(6): 949-54.

178. Koller W, Biary N, Cone S. Disability in essential tremor: effect of treatment. Neurology. 1986;36(7):1001-4

179. Louis ED, Okun MS. It is time to remove the 'benign' from the essential tremor label. Parkinsonism Relat Disord. 2011;17(7):516-20.

180. Zubair A, Cersonsky TEK, Kellner S, Huey ED, Cosentino S, Louis ED. What Predicts Mortality in Essential Tremor? A Prospective. Longitudinal Study of Elders Front Neurol. 2018:9:1077.

\section{Publisher's Note}

Springer Nature remains neutral with regard to jurisdictional claims in published maps and institutional affiliations.

\section{Ready to submit your research? Choose BMC and benefit from:}

- fast, convenient online submission

- thorough peer review by experienced researchers in your field

- rapid publication on acceptance

- support for research data, including large and complex data types

- gold Open Access which fosters wider collaboration and increased citations

- maximum visibility for your research: over $100 \mathrm{M}$ website views per year

At $\mathrm{BMC}$, research is always in progress.

Learn more biomedcentral.com/submissions 